\title{
Debate about science and religion continues
}

I commend Murray Peshkin for his personal involvement in educating the public about science (PHYSICS TODAY, July 2006, page 46). Arming nonscientists with even the most basic scientific reasoning goes a long way in dispelling much of the misinformation propagated by religious fundamentalists. However, I think Peshkin's explanation of boundaries between science and religion is wrong, and even though his education of nonscientists is amiable, his message to the religious among them is condescending.

Peshkin's presentation to religious nonscientists is conciliatory through the claim that science need not overlap with their beliefs, and that they can be safe from scientific scrutiny because science and religion have "different rules of inference, and different definitions of truth or reality." The statement comes without explanation and seems like it is intended to be accepted without question by a receptive audience. Then he writes, "Science is based entirely on experiment," which emphasizes a narrow scope of science and implies ample room for religious belief. This second statement is wrong because it disregards the role of observation, something responsible for astronomy and much of evolutionary biology, to name just two areas. By neglecting to mention observation in this context, he leaves out the essence of science most directly responsible for unease with religion. Specifically, observation means that many religiously motivated claims about nature can be subject to scientific scrutiny even if they are not experimentally accessible; the origins of the universe and of humans are prime examples. Science has cornered religious assertions about the natural world, and

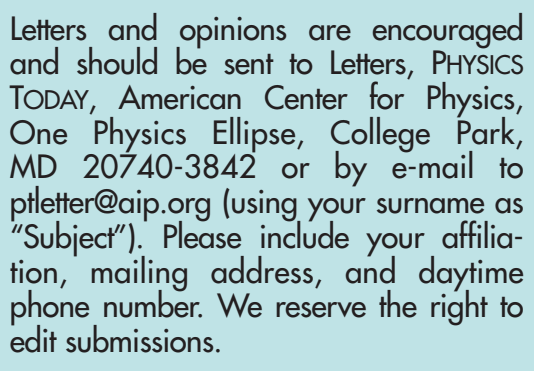

Letters and opinions are encouraged and should be sent to Letters, PHYSICS TODAY, American Center for Physics, One Physics Ellipse, College Park MD 20740-3842 or by e-mail to ptletter@aip.org (using your surname as "Subject"). Please include your affiliation, mailing address, and daytime edit submissions. the tension arises not when scientists step over some imaginary line into religion but when religion trespasses by trying to explain the natural world. Any supernatural cause that has an effect in the natural world is subject to validation or refutation by science.

Peshkin does give two examples where science cannot tread: "The world was created three hours ago with all our memories and everything else in place," and "No observational evidence can disprove some subtle supernatural intervention." But those statements are just specific examples of the general rules; we can't know the unknowable, and we can't disprove the existence of something. Peshkin seems to imply that these kind of fantastical ideas are a refuge for the religious, without enlightening them to how extremely small a perimeter it leaves them to roam. He does not show, for example, how this fence surrounding religion means the effectiveness of prayer, existence of the soul, and interaction between a deity and the natural world are subject to scientific scrutiny. Instead, his misrepresentation of science appears deliberately designed to comfort those with beliefs in the supernatural.

My charges present a dilemma for Peshkin and for all of us who want to have an honest debate about science education, health care, medical research, and other avenues in which science and religion have rubbed elbows. Either we run the risk of alienating religious people by explaining how little room science leaves for mysticism, or we treat them like children by sugarcoating our empiricism so they can feel comfortable in their beliefs; the latter stance is often mistaken as respect for religion. Perhaps Peshkin's middle ground is good diplomacy, but it is not completely forthright.

Michael Matthews (mikematthews@yahoo.com) Austin, Texas

There is much wisdom in the example Murray Peshkin sets and in the specific topics he mentions. However, as someone who has moved in my career from physics to planetary science to astrobiology, I am sensitive to two areas in which Peshkin's approach risks sending the wrong message.

The meaning of the word "theory" has evolved over the past century to the point where no one outside of a few academic oases uses its original scientific meaning. Such establishment bastions as the New York Times and National Public Radio, and even many scientists in ordinary conversation, use theory to mean an idea, suggestion, or hypothesis. Common are such phrases as "in theory, such-and-such is true, but in practice..." or "in the absence of evidence, several theories were suggested." It is certainly possible to explain to a captive audience that the scientific meaning of this word is almost the exact opposite of its colloquial usage. Much better, however, is to talk about gravitation, relativity, plate tectonics, or evolution without the word "theory." We are likely to communicate more effectively if we do not demand that a lay audience unlearn the familiar meaning of this word.

My second concern is the description of science as based entirely on experiment. We must broaden the definition to include observation and inference about things that have happened in the past or are happening in the universe beyond Earth, since those are the topics that generate the most controversy between science and religion.

David Morrison (dmorrison@arc.nasa.gov) NASA Ames Research Center Moffett Field, California

The ongoing national debate about the teaching of evolution in our public schools is best served by clearly distinguishing the experimental sciences from the historical sciences like Darwin's theory of evolution. The historical sciences invariably bring into play the totality of the human experience and thus the debate.

Scientists, philosophers, and theologians accumulate knowledge when analyzing different aspects of reality and search for particular hypotheses or models to fit their respective subject matters. Of course, a main goal is to integrate these kinds of knowledge into an all-encompassing worldview. 
Religious concepts and beliefs are based on the notion of divinity, so one must posit the existence of the supernatural, which transcends nature but may contain all or part of it. The overwhelming majority of Americans subscribe to the existence of such a realm.

A first, reasonable, and useful definition of science is the study of the physical aspect of nature, and its subject matter is data that can be collected, in principle, by purely physical devices. Therefore, the laws of experimental science are generalizations of historical propositions - that is, experimental data. Note that consciousness and rationality are purely nonphysical, since purely physical devices cannot detect them. In addition, life cannot be reduced to the purely physical, so living beings are both physical and nonphysical.

Human rationality develops formal logic and creates mathematics to summarize data into laws of nature that lead to theoretical models covering a wide range of phenomena. However, scientists deal with secondary causes. First causes involve metaphysical (ontological) questions, which regulate science. Without the ontological, neither the generalizations nor the historical propositions of the experimental sciences would be possible.

An extreme form of reductionism supposes that all that exists is purely physical and that the nonphysical aspect of reality follows from the purely physical and the laws governing their interactions. Unfortunately, this is often what is in the mind of the public when discussing evolution. For that reason, one must spell out what prior information is assumed in evolutionary theory; otherwise, people would associate Darwin's evolution with a particular worldview, for instance, atheism. In addition, it ought to be emphasized that advances in medicine and other practical applications of biology are based essentially on the results of laboratory experiments and not the history of the evolution of life on Earth.

The public should be made aware that the laws of experimental science are quite consistent with most theological presuppositions. It is in the study of unique historical events - say, in cosmological or biological evolution-where the conflict between science and religion may arise. For instance, the Christian faith is based solely on the historicity of Jesus of Nazareth, his death, and his resurrection. Absent those historical events, there would be no Christian faith. Experimental science has nothing to say regarding any particular historical event.

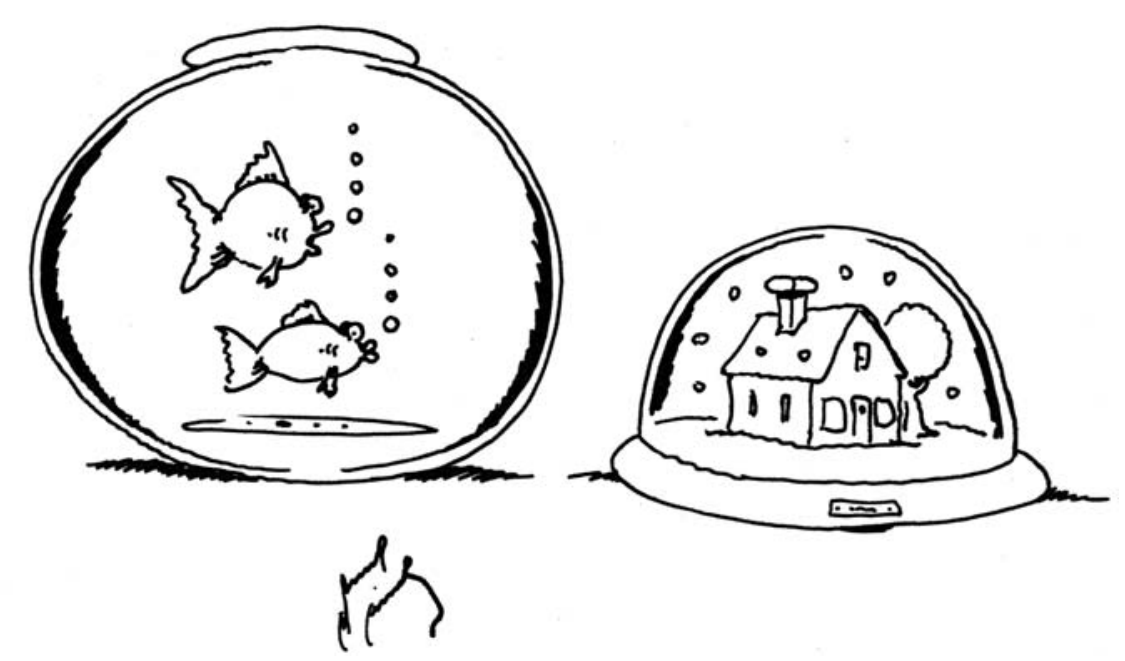

"Oh great! Now l'll have to form a whole new cosmology."

Isaac Newton's mechanics and James Clerk Maxwell's electrodynamics are excellent prototypes of scientific theories. No designer or theological considerations are needed in the theories themselves except when considering the nature of the humans who created the mathematical schemes. Therefore, the consideration of humans in any theory must be based on the integration of science with other kinds of knowledge-theology, for example.

The question of origins, especially the origin of man, poses a most difficult problem-in particular, the emergence of life from the purely physical. Surely, the results of experiment are used to analyze all extant data in the historical sciences; nevertheless, the fundamental problem of origins is more a historical rather than a scientific problem.

Finally, Peshkin indicates, "a proposition is not a scientific theory at all unless it's falsifiable in principle." Of course, if one is to apply Karl Popper's principle of falsifiability, a theory must make unambiguous predictions. In weather forecasting, the physics underlying the dynamics is well known, and given the initial conditions, longrange forecasting is very limited indeed. Surely, the evolution of life on Earth is a much more complex system, so the claims made by those advocating evolutionary theory can never really be falsified.

\section{Moorad Alexanian (alexanian@uncw.edu) University of North Carolina Wilmington}

The issues of scientific validity and science versus pseudoscience were never addressed in any courses I took as an undergraduate science major, and I observe the same situation in today's university introductory science courses. How are undergraduates - or graduate students, for that matter-supposed to learn these things? Murray Peshkin is correct when he says, "We need to do better."

For about the past five years, I have begun my introductory astronomy courses with a detailed interactive talk on the nature of science and critical thinking. I incorporate a study of logical fallacies, another item missing from most science courses. I use actual letters to the editor of the local newspaper as debunking fodder. This introduction to critical thinking takes about two weeks, but by the end of the semester, my students know how to tell science from pseudoscience and belief, and they know how to gauge the scientific validity of a claim. Instructors who leave this material out of their courses are doing a great injustice to students and to science in general. The presentation I use in my classes is available on my website http://www.sticksandshadows.com) along with a small but growing collection of custom applications of critical thinking to astronomy.

All introductory science courses should be built around critical thinking, with examples from the various scientific disciplines providing applications. If students never understand the nature of science, they will never truly understand how and why we know about exotic entities like black holes.

My experience has been that students welcome discussion on the differences between science and religion, a necessary topic when it comes to criti- 
cal thinking. In a recent semester, three students told me they were planning to become ministers, and they appreciated the opportunity to develop criticalthinking skills. One of these students told me that elders in his church warned him to avoid science classes because they would be a waste of time and would not help him become a better minister. How much clearer does the need have to be before we do something about it?

Joe Heafner (heafnerj@sticksandshadows.com) Catawba Valley Community College Hickory, North Carolina

The debate about the teaching of evolution in public schools is unique to the US among Western countries. ${ }^{1}$ Murray Peshkin's admonition to the scientific establishment to engage in mature discussions of the issues involved must be taken seriously. But such endeavors need careful preparation.

First, several facts should be taken into account explicitly. Most religions are focused on the human being, with the universe-prime target of the physicist's professional dedicationrelegated to playing a supporting role. In religion, spatial and temporal dimensions are those familiar to human experience, information about the universe is that which can be acquired through our senses, and relevant causal interconnections between events are those whose consequences directly affect us. It is then quite natural that phenomena extending over a few hundred human lifetimes and images like the Earth orbiting around the Sun-which we never actually see happening - were met with resistance for a long time. Even today, the scientifically uninformed public has little comprehension of astronomical and geological scales; everything that invokes them is perceived as "just a theory." The same applies to the fact that order can emerge out of chaos and purposeful behavior out of random events without any outside intervention except for some available energy and the action of a few universal physical laws. Scientifically uninformed people sense, based on subjective experience, that purposeful complexity cannot just emerge but must be designed-without being aware that self-organization occurs in so many everyday phenomena.

Second, we should recognize that coexistence, even cooperation, between faith and science is possible, though it does require some compromises. People of religious faith should recognize that one cannot challenge scientific facts

www.physicstoday.org with ideas alone and that many more unforeseen natural phenomena revolutionizing previously held worldviews may still be discovered. Scientists, in turn, should recognize that some people-including some scientists - will always need religion for spiritual guidance and comfort and will always have questions concerning the "why of things" to which the scientific method cannot provide answers. Religion should turn away from a literal interpretation of its sacred scriptures by recognizing when they were written, by whom, for whom, and for what purpose. Science should turn away from the easy way out offered by the anthropic principle and recognize that natural points of contact between science and religion do exist. Those points include some questions concerning the values of the universal constants; the actual form of physical laws; and the key fluctuations that gave rise to the Big Bang, the appearance of the first living organisms, and the emergence of selfconsciousness.

Third, we should be aware of what some influential personalities have declared about the matter. Pope John Paul II stated, "Science can purify religion from error and superstition, and religion can purify science from idolatry and false absolutes," and "The Bible itself speaks to us of the origin of the universe and its makeup, not in order to provide us with a scientific treatise but in order to state the correct relationships of man with God and with the universe." 2 And Werner Heisenberg wrote,

Science deals with the objective, material world.... Religion, on the other hand, deals with the world of values. It considers what ought to be or what we ought to do, not what is. In science we are concerned to discover what is true or false; in religion with what is good or evil, noble or base. Science is the basis of technology, religion the basis of ethics. ${ }^{3}$

As a physicist, I like to view scientific thought and religious faith as "basis states" of the human brain: They are mutually orthogonal, but at any given time the actual state of the brain can be a superposition of the two without violating the principles of either. Any attempts to force a collapse into one or the other, like the so-called scientific creationists and some agnostics would wish to do, go counter to the very nature of human brain function. In fact, predisposition for religious beliefs and the search for scientific knowledge may even have a

February 2007 Physics Today 13

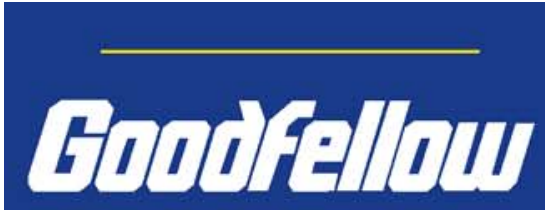

The \#l source for

METALS \& ALLOYS

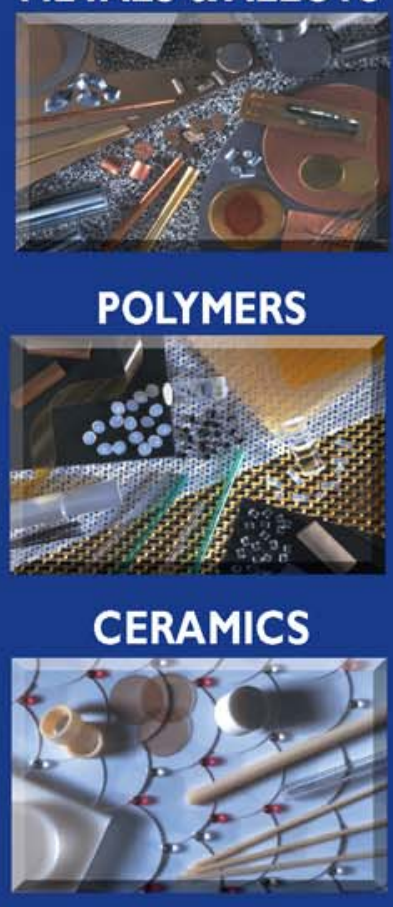

COMPOSITES

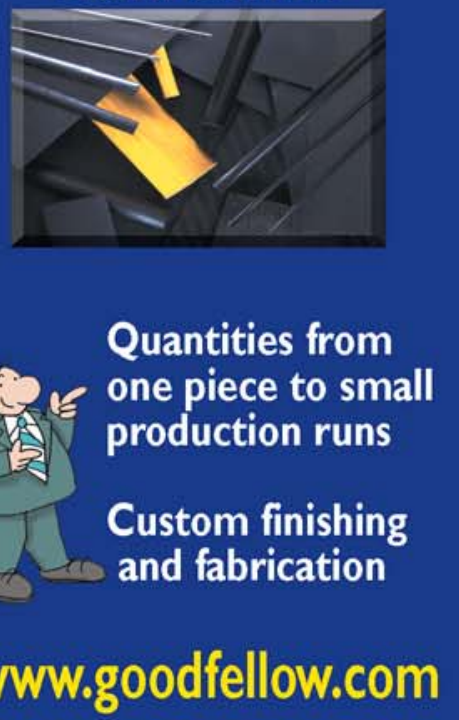

Save $5 \%$ on online orders

$|-800-82|-2870$

fax I-800-283-2020 info@goodfellow.com

(C) 2005 Goodfellow Corporation 
common evolutionary origin: ${ }^{4}$ the human brain's conception of time, its unique capability of creating images of the future and making long-term predictions, the innate urge to do so, and a feeling of satisfaction when it is done.

\section{References}

1. A. Lazcano, Science 310, 787 (2005).

2. R. J. Russell, W. R. Stoeger, G. V. Coyne, eds., Physics, Philosophy, and Theology: A Common Quest for Understanding, Vatican Observatory, Vatican City (1988), pp. 14, 29.

3. W. Heisenberg, Physics and Beyond: Encounters and Conversations, A. J. Pomerans, trans., Harper \& Row, New York (1971), p. 82.

4. J. G. Roederer, Information and Its Role in Nature, Springer, New York (2005), pp. $163,220$.

Juan G. Roederer (jgr@gi.alaska.edu) Geophysical Institute University of Alaska Fairbanks

As a chemical physicist I have followed both chemistry and physics for more than 40 years. In recent years, I have noticed a gradual change in the language of physics. Physicists now are more willing to accept that our knowledge may be limited and to admit that we will probably never be able to answer the major questions of existence that also fall in the realm of religion. In fact, some modern physics theories are beginning to require a certain belief system of their own and could be criticized as to whether they remain science (Burton Richter discusses this in his Reference Frame in PHYSICS TODAY, October 2006, page 8). This change has been noteworthy and has provided for a healthier self-analysis by many physicists. However, I was a little shocked by the Opinion piece by Murray Peshkin, a theoretical physicist. It indicated, unfortunately, that the old arrogance of physics is still very much alive. It appears that a theoretical physicist is needed to present both Darwin's theory of evolution and religion to the general public to help resolve any conflict and emphasize that the theory is supported by extensive experimentation. Peshkin apparently has never read Fred Hoyle's book Mathematics of Evolution (Acorn Enterprises, 1999), which severely criticized the theory and outlined its limitations. Many chemists and physicists have great trouble with Darwin's theory, especially if one tries to extrapolate it to higher life forms or modify it from an evolutionary concept to one of creation. If scientists cannot agree no wonder the general public is confused. I am still amused that even NASA justifies some of its programs in the belief that creation of life forms is some simple mechanism and with luck will be easily found somewhere else.

To extrapolate from nothing to the incredibly complex DNA-replicating molecule takes an even greater leap of faith than any religion. If I give a talk to a general audience, I emphasize the severe limitations of science and our lack of true understanding. We have good models and theories and have made great advances, but we still confuse data and the accumulation of knowledge with true understanding. Moreover, because of our apparently superior knowledge, some people now accept science as their religion.

The older I get, the more I recognize the great commonality between the sciences and the arts. In reality, science is no more than the technical branch of the arts. For example, who was more talented: Albert Einstein, Ludwig van Beethoven, Leonardo da Vinci, or William Shakespeare? Each discipline requires ingenuity, creativity, and insight. One would hope also some wisdom but that is an area that still needs more emphasis and is not taught or easily acquired.

Keith Schofield (combust@mrl.ucsb.edu) University of California Santa Barbara

Being a PhD geneticist and a creationist, I was disappointed that Murray Peshkin did not give references for the statement "Hundreds of Darwin's predicted missing links have been found." I find quite the opposite. The scientific turmoil behind whether birds are descendants of dinosaurs is but one example of how the popular press does not accurately reflect the disagreements in the scientific community. As Storrs Olson, curator of birds for the Smithsonian Institution, stated in a 1999 letter to National Geographic,

The idea of feathered dinosaurs and the theropod origin of birds is being actively promulgated by a cadre of zealous scientists acting in concert with certain editors at Nature and National Geographic who themselves have become outspoken and highly biased proselytizers of the faith. Truth and careful scientific weighing of evidence have been among the first casualties in their program, which is now fast becoming one of the grander scientific hoaxes of our age-the paleontological equivalent of cold fusion.
If Peshkin could provide some solid references, it would add credibility to his opinion.

Also, equating Charles Darwin's and Gregor Mendel's theories does not work for me. Mendel observed inheritance patterns and developed a theory of Mendelian genetics, which is verifiable in simple reproducible experiments. His theory of genetic inheritance provides the mechanism for natural selection, which is observable. Darwin, on the other hand, postulated that natural selection would extend to species changes and therefore provide the mechanism for macroevolution. I have never found that to be observable. As traits are favored through selection, genetic information is reduced, not increased. Man's very behavior exhibited through gene conservation activities is evidence that genetic information is not gained, as required for macroevolution to occur, but is actually lost.

\section{Michael Todhunter} (m.todhunter@att.net) Bristol, Connecticut

Peshkin replies: We scientists need to teach the nonscientist public what science is about: what an established theory is and how we know when it's right; how the requirement of falsifiability serves as a fence between science and nonscience, defining the limitations of science and insulating it from attacks based on pseudoscience; and especially why science, correctly understood, does not threaten most people's religious beliefs.

Michael Matthews says that the approach I advocate is condescending to the religious. It has not been so perceived by the several dozen people who have approached me after my public lectures or in response to my writings for the public. A majority of the many who identified themselves as people of religious faith, from high-school students to the former president of a theological seminary, started the conversation by saying that they appreciated my respect for religion. Nevertheless, Matthews's warning should be heeded. People can be hypersensitive to unintended slights about their religion, especially slights from scientists. If you do not have respect for people's religion, you should not be conducting such discussions; if you do have that respect, you should make it obvious from the outset. You don't have to pretend to share your audience's religious beliefs; you only have to respect them. Otherwise, people will tune you out.

Matthews misrepresents the fence I described. It surrounds - and is defined 
by the demands of-science, not religion. Nobody can reasonably deny religion its own perspectives regarding natural phenomena as well as religious beliefs. Science's fence is violated only if a pretense is made that such a discussion is science when it is not. That point of violation is the reason for the conflict, and that is where we have to guard against attempts to substitute pseudoscience for science in our schools. Explaining the conflict to the public has not been made easier by recent contemptuous attacks on religion by atheists who are scientists but who abuse science when they claim falsely that it disproves religion. I explicitly disown such attacks and advise others to do the same.

Matthews, joined by David Morrison and Moorad Alexanian, also objects to my use of experiment as the sole criterion for defining science; they say observation is also part of science. They are right. Henceforth I will say "experiment and observation," but that alone does not address the substance of their complaint. The subtleties of the difference between experiment and observation and their interaction with predictive power and falsifiability may be suitable for advanced students, but they cannot usefully be addressed in a typical one-hour general-interest lecture, at least not by me. Each person who gives such talks has to use an approach with which he or she is comfortable. I am comfortable with describing the discovery of the cosmic microwave background as a make-orbreak experiment that could have falsified the Big Bang theory. Big Bang cosmology was on a back burner until the CMB was predicted and subsequently discovered. Was that an experiment or an observation? I don't think it matters. An example from geology is the speculation that the K-T extinction was caused by a meteor impact. That idea became generally accepted when its prediction of a global iridium-rich layer at the right depth was confirmed experimentally - or was it observationally? Absent that widespread iridium, the theory would have been falsified. That's what made it science.

Testing the theory is more difficult in biology. Biologists can tout simple individual experiments and observations that test evolution, but biologists are also dependent on the overall success of the big picture, the observation of which must agree with their theories. I defer to the biologists for an authoritative description of all that. My point is that what is science and what is not remains the same.
Morrison also suggests that we drop the word "theory" because it has diverse meanings. Particle physicists and astrophysicists often do just that, speaking instead of "the standard model." I see no useful answer to the argument that evolution is "just a theory" other than to explain what an established scientific theory is and why it must be respected despite our near certainty that future research will find its applicability limited.

Alexanian says that experiments to test evolution's description of the origin of the earliest life forms are not possible. We can never prove that any theory is true; we can only challenge it with tests. The famous Miller-Urey experiment and its successors, in which amino acids were created from hydrogen, methane, carbon dioxide, and water in a process that credibly mimics nature, constitute such a test.

Joe Heafner serves his students well by discussing the nature of evidence and related questions. I hear anecdotally that others are beginning to do the same. I hope they will all emphasize the limitations of science and why science and religion, reasonably understood, do not threaten each other.

Juan Roederer addresses issues that go beyond the conflict we currently face in our schools and our courts. He seeks a generalization of science and religion into a philosophy that not only includes both but creates a unified system in which the two are non-trivially entangled and which satisfies the core needs of both. The clarity with which Roederer describes that ambitious quest in a short letter is remarkable. However, its success is uncertain, as is the time scale on which we will learn whether it succeeds. Protecting the teaching of good science in our public schools cannot wait. We must defend the science we have, which is distinct from religion, and we must do it now.

I note that Roederer enjoins science to "turn away from the easy way out offered by the anthropic principle." But observations of atomic spectra in distant quasars hint at a slight shift in the fine structure constant. If that result is confirmed, the improbability of finding conditions right for life somewhere at some time becomes at least a semiquantitative question that needs to be investigated by the methods of science.

Keith Schofield makes three substantive points: that his experience as a chemical physicist leads him to believe that DNA cannot have arisen in a natural process, that physicists should butt continued on page 81

February 2007 Physics Today 15

New low pricing $4 K$ ARs Displex Pneumatic Drive Gryocoolers .8W @ 4-2K DE-2105 25w @ 4.2K DE-2045 .1w @ 4-2K DE-2025

Research \& OEM Gryostats

Optical $\&$ Non Optical

True UHV (10 ${ }^{-11}$ ton)

Low Vibration Interface (5 nanometers)

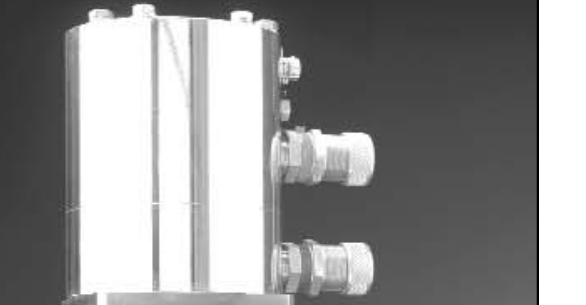

西

\section{.}

.

$$
\text { 西 }
$$

\footnotetext{
.
}

$$
\text { 西 }
$$

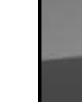

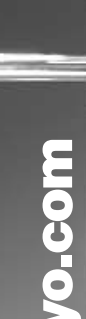
www.physicstoday.org 
out and leave the discussion to biologists, and that scientists have a faith of their own. The first is asserted without explanation and the second seems curious in light of the first. Schofield's third point is interesting. I think most scientists take on faith that there is some understandable pattern to the things we can observe, that we are on the right track in investigating that pattern by the methods of science, and that we are closing in on something that corresponds to our intuitive idea of reality. That belief is a matter of our metascience, or perhaps of our psychology, not part of the science itself, which deals only with the observable world. The important thing for the present discussion is that this belief neither confirms nor contradicts religion.

Michael Todhunter asks to debate the evidence for evolution in the fossil record. Books have been written on that subject-I cited two in my Opinion piece. The practical political issue is this: What should our public schools teach when confronted with disagreements they are not themselves able to resolve? The answer is easy. Almost all the most respected biologists are saying that evolution is the theory that works and that it is the central organizing principle of modern biology. If the school boards have any sense, that is what their schools will teach despite a few dissenters, some of whom offer genuine scientific challenges to the theory and most of whom have other agendas. The schools should be teaching their students that all theories have wrinkles that remain to be ironed out. They should be teaching that all theories are tentative and our understanding is always incomplete, but that science progresses by building on what we know best. Well-established theories such as evolution work too well not to have mostly permanent truth in them, even though the theories will evolve in response to new evidence. We should be helping the school boards by educating their constituents.

Contrary to Schofield's advice, all kinds of scientists should be explaining to the public what science is about and emphasizing its strengths and its limitations, because the public and not the courts will decide where this country will go in the 21st century.

Murray Peshkin Argonne, Illinois
US lacks nuclear-power
infrastructure

I read with great interest the hopeful items about the coming nuclear power boom (PHYSICS TODAY, February 2006, pages 11 and 19), but I would like to point out that the US has lost the infrastructure to build these plants. Because of economics, the US no longer has the heavy industry capable of building the reactor heads and steam generators that new plants require. Reactor owners looking to replace aging plant components must contract with Japanese, Korean, or Italian companies for the heavy forging and machine work that was once done in America, and compete against other interests for both valuable plant time and floor space to get their components finished. American nuclear plants are just not a 600-pound gorilla that can command the marketplace anymore.

America is also losing the quality battle for smaller components such as pumps, valves, and circuit breakers. Many of the smaller vendors and foundries that once produced pumps, piping, and valves to the ASME Boiler and Pressure Vessel Code (a nuclear requirement) have been swallowed up by mergers, leaving only a few suppliers. And those few have had little incentive to keep a costly quality program that meets the requirements of a nuclear supplier as defined in the Code of Federal Regulations (10CFR50, appendix B) because the market for nuclear replacement parts is scant. Other suppliers have lost control of their quality programs because of such factors as offshore production and the loss of tribal knowledge due to an aging workforce and downsizing.

This isn't to say that America won't produce new nuclear power generating stations, but a lot of infrastructure investment will be needed to bring the US back to the level where we can make them using American resources and labor.

Jim McEwen (starsekr@aol.com) Oceanside, California

\section{Training teachers for college}

I have enjoyed the articles about physics education that have appeared in the past several months. They have generated a great deal of knowledge that needs to be integrated into educa- tional programs at all levels. However, I have noticed that much of the discussion about training has focused on $\mathrm{K}-12$ teachers, who are trained in the baccalaureate education programs of colleges and universities. This focus is important, but it avoids a long-standing problem: how to train college and university professors.

Professors are rarely required to have taken education courses, yet they must usually demonstrate a dedication to teaching and state some philosophy of teaching. A prospective professor's approach to teaching must apparently be developed independently. Most physics professors have developed their approaches to teaching through their experiences as graduate students and postdocs.

I believe that current and prospective professors would be well served by a series of courses or training sessions, implemented at many colleges and universities worldwide, that distill current physics education knowledge and provide a venue for practicing it with other students. The courses could be offered as part of undergraduate or graduate curricula or in pre-employment or professional-development training sessions. Alternatively, training sessions could be implemented as an ongoing part of the annual conferences of the various scientific professional societies, and then funding could be secured for conference attendees. (This approach could also work for $\mathrm{K}-12$ teachers.) Implementation of training courses would be helpful not only to current professors but also to those who, like me, are employed in industry but would eventually like a teaching career.

Thomas Wofford (thomas.wofford@ara.com) Applied Research Associates, Inc Albuquerque, New Mexico

\section{Diverse thoughts on diversity in physics}

I read Shirley Malcom's “Diversity in Physics" article (PHYSICS TODAY, June 2006, page 44) with great interest. As a physics student in college, I often marveled at just how white and male all of my classmates and professors were.

I have been teaching physics for four years in a public high school in Massachusetts, and I think I can address at least one piece of the puzzle. In my first year as a teacher, I made the classic novice error of teaching as I had 